\title{
АНАЛИЗ ПРОБЛЕМ ПРИ ПОДГОТОВКЕ И ПРОВЕДЕНИИ ГИА
}

\author{
Дубайлова Ольга Леонидовна \\ председатель ЦМК УГС: Машиностроение \\ ГАПОУ Туймазинский \\ индустриальный колледж
}

\section{1 слайд}

Защита выпускной квалификационной работы (ВКР) является завершающим этапом образовательного процесса и важным инструментом итогового государственного контроля качества подготовки выпускника.

Государственная итоговая аттестация выпускников по специальностям 15.02.08 и 15.02.01 проводится в форме подготовки и защиты дипломного проекта. ВКР способствует систематизации и закреплению знаний выпускника по специальности, а также выяснению уровня подготовки к самостоятельной работе.

В отчетах ГЭК отмечается, что выпускники колледжа владеют общими и профессиональными компетенциями для осуществления соответствующих видов профессиональной деятельности. Определённая часть выпускников имеет четко сориентированные цели на продолжение обучения в высших учебных заведениях.

Значительная часть выпускников понимает и придает должное значение необходимости постоянного профессионального самосовершенствования и самообразования.

Выпускники колледжа в ходе государственной итоговой аттестации демонстрируют готовность при реализации профессиональных функций решать поставленные задачи, требующие анализа ситуации и выбора решений; подготовленность к использованию информационно-коммуникационных технологии в профессиональной деятельности; способность осуществлять поиск и использовать информацию, необходимую для эффективного выполнения профессиональных задач, профессионального и личностного развития.

Вместе с тем анализ отчетов ГЭК и материалов экспертиз ДП позволил выявить недостатки и сформулировать рекомендации, реализация которых способствовала бы улучшению качество подготовки выпускников. 


\section{2 слайд}

Анализ ВКР показывает, что происходит рост качества: 17-18 год-4,58, 18-19 год-4.6 средний балл, исключение прошлый 19-29 год-4,0. и в прошлом учебном году оно составило 98\%. При этом количество «красных дипломов» стабильно, приходится по одному на каждый выпуск.

Обобщение и группировка замечаний позволяет свести их к следующему:

- наблюдается нарушение требований по оформлению пояснительной записки и графической части от ЕСКД и ГОСТ;

- применяются устаревшие ГОСТы;

- недостаточно используются новые конструктивные решения;

- отсутствует проработка и понимание экономической части;

- не в полной мере используется программное обеспечение для расчетов в различных разделах ДП;

- не во всех работах обоснована актуальность выбранной темы, нет обоснованности выводов и предложений авторов;

- не во всех рецензиях имеются критические замечания;

- низкий уровень докладов при защите выпускных работ;

- не все руководители дипломных проектов используют разработанные стандарты предприятия;

- небольшой процент тематики ДП по заказам предприятий, имеющими практическую значимость;

- низкий уровень требований к оформительской и содержательной частям дипломных проектов.

В отчётах ГЭК есть и другие замечания более частного порядка.

\section{3 слайд}

Качество подготовки к Государственной итоговой аттестации (ГИА) это интегральная характеристика, в которой можно выделить следующие составляющие:

1. Качество процесса обучения (деятельность педагогического коллектива в целом и каждого его субъекта в отдельности).

2. Качество условий (научно-методических, управленческих, организационных, психологических, материально-технических и др.)

3. Качество (квалификация) педагогов. 


\section{4 слайд}

Можно выделить несколько направлений для успешной подготовки и защиты ВКР.

\section{1. Повышение уровня подготовки участников ГИА}

Для выполнения дипломного проекта необходим определенный уровень подготовки, как студента, так и руководителей, поэтому необходима планомерная подготовка к подобному роду деятельности.

Не смотря на то, что преподаватели колледжа накопили большой опыт в руководстве дипломным проектированием, должна быть общая методика данного процесса, должен происходить обмен опытом и инструментами в этой области. Взаимообмен полезными наработками позволит усовершенствовать работу преподавателей в области руководства дипломными проектами и сформулировать общие подходы к этой деятельности.

Подготовка студента к дипломному проектированию требует системности и последовательности. Необходимо на протяжении всего обучения привлекать студента к участию в научно-практических конференциях, конкурсах профессионального мастерства, олимпиадах, семинарах. Опыт в публичных выступлениях позволит студентам своевременно получить необходимый опыт и не допускать ошибок во время защиты ДП. Нужно, чтобы студент к моменту выхода на производственную практику был готов к самоопределению и выбору темы дипломного исследования, а к моменту написания работы смог максимально использовать свои способности в обработке информации, ее анализе и визуализации.

\section{2. Мотивация}

На успешность процесса обучения значительное влияние оказывают интересы, мотивы, ценностные установки и потребности студента, его навыки в получении и переработке информации, а также общеобразовательная база. Как показывает практика, чем выше уровень всех этих личностных компонентов студента, тем успешнее проходит его обучение и достигаются более высокие конечные результаты.

Для повышения уровня мотивации студентов с целью улучшения качества подготовки выпускных квалификационных работ, возможно:

- проведение конкурсов на лучший дипломный проект (работу).

При оценивании можно руководствоваться такими критериями, как новизна и оригинальность предлагаемых технических и технологических 
решений, практическая важность полученных результатов, качество оформления графической части и пояснительной записки, общеинженерная эрудиция и культура, уровень использования компьютерных технологий, качество доклада и умение аргументированно отстаивать свою точку зрения и Т.П.

- Одним из действенных методов стимулирования учебной и деловой активности студентов является метод портфолио.

Портфолио (англ. portfolio - портфель, папка для важных дел или документов) - собрание документов, образцов работ, отзывов, фотографий, дающих представление о предполагаемых возможностях студента. Каждому студенту нужен внутренний инструмент оценивания, который бы мотивировал студента «изнутри» и опирался бы на его внутренние потребности и мотивы саморазвития. Особую весомость портфолио наших студентов придает участие в чемпионатах по стандартам WorldSkills Russia, как на региональном, и тем более на национальном уровнях.

Таким образом, портфолио - современный способ точного оценивания имеющихся у студентов основных компетенций, а также перспектив его эффективного взаимодействия с будущим работодателем. Портфолио, если представлять его вместе с защитой дипломного проекта, может стать эффективным способом продвижения будущих специалистов - выпускников колледжа - на рынке труда.

\section{5 Слайд}

- Мотивирующий момент - периодическая публикация готовности ДП на конкретную дату. Сравнение, сопоставление собственных успехов с успехами одногруппников, не дает выпускнику расслабиться, предоставлять работы с отставанием от графика и т.п.

\section{3. Информированность}

Помимо разработанных методических рекомендаций по подготовке и защите ДП, можно рекомендовать проведение семинаров, где руководитель подробно расскажет о процедуре защиты и ответит на вопросы студентов. Можно проводить предварительный просмотр защиты, воссоздавая еe реальные условия.

\section{6 Слайд}

Оформление стенда в помощь дипломнику также поможет сориентировать студента в правильной организации подготовки к ГИА (рис.1) 


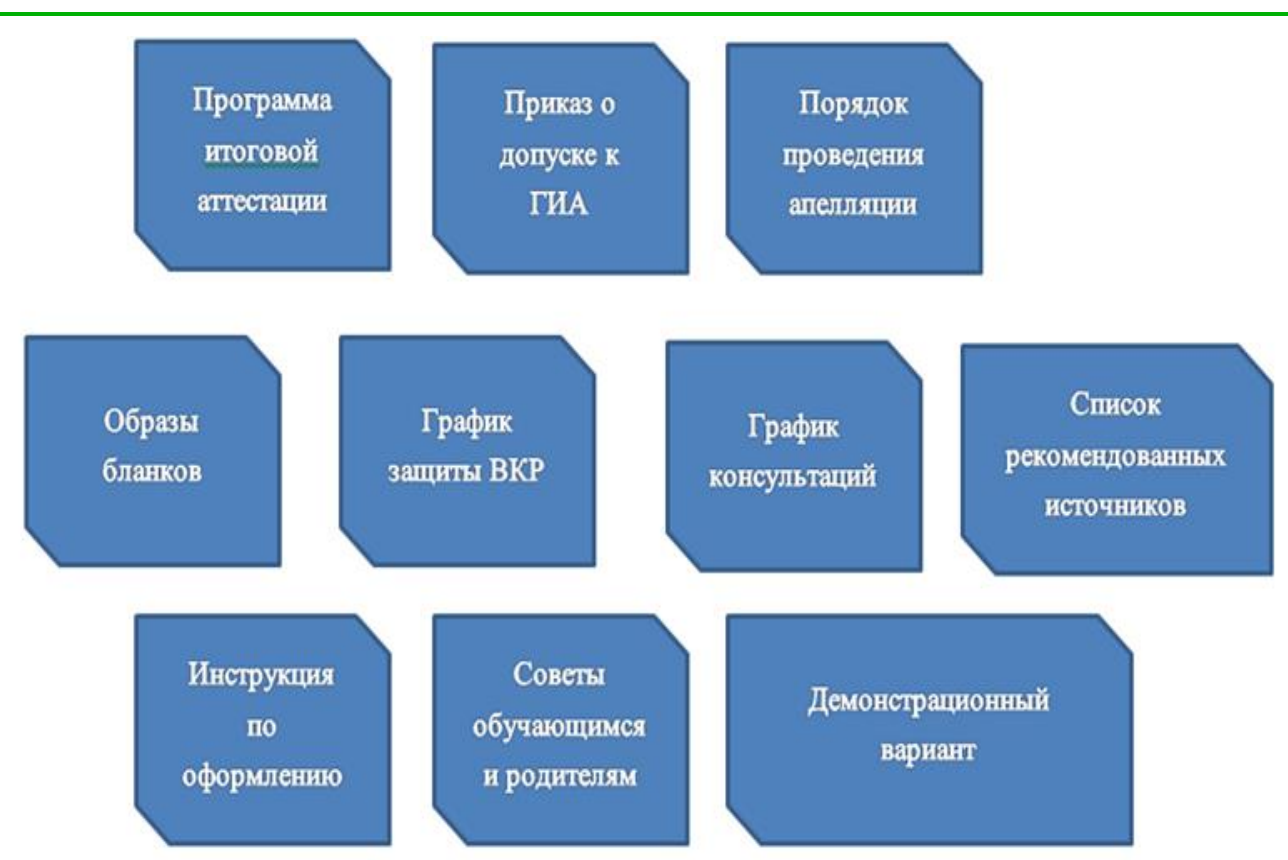

\section{Рис. 1. Оформление уголка подготовки к ГИА}

\section{4. Психологическое сопровождение}

С точки зрения психологических особенностей обучаемых, можно заключить, что практически все они в процессе учебы нуждаются в одобрении, в поощрении со стороны окружающих, в достойной оценке результатов труда. Студенты колледжа находятся в том возрасте, в той фазе своего личностного развития, когда вопросы самолюбия и одобрения их деятельности носят принципиально важный характер. Здесь необходима совместная деятельность, как администрации, педагога-психолога, так и куратора, педагогов для создания позитивной обстановки, направленной на плодотворную работу по выполнению выпускной квалификационной работы (табл.1).

\section{7 Слайд}

\section{Таблица 1}

\section{Психолого-педагогическое сопровождение при подготовке к ГИА}

\begin{tabular}{|l|l|}
\hline Участники & Функции \\
\hline Зам. директора по УМР & -Планирование и координация всех участников \\
& ОО при подготовке к ГИА \\
& -Информирование о ГИА \\
& -Организация и проведение ГИА \\
\hline
\end{tabular}




\begin{tabular}{|c|c|}
\hline Куратор & $\begin{array}{l}\text {-Формирование позитивного отношения к ГИА } \\
\text {-Оказание всесторонней помощи, обучающимся на } \\
\text { протяжении всего периода подготовки и } \\
\text { проведения ГИА } \\
\text {-Индивидуальная работа с отдельными студентами, } \\
\text { имеющими проблемы в обучении, } \\
\text { или претендующими на красный диплом } \\
\text {-Ориентирование студентов на успешную } \\
\text { защиту ВКР }\end{array}$ \\
\hline Психолог & $\begin{array}{l}\text {-Формирование положительного отношения к ГИА } \\
\text {-Разрешение психологических трудностей } \\
\text {-Формирование и развитие } \\
\text { определенных психологических знаний, } \\
\text { умений и навыков, необходимых для } \\
\text { успешного прохождения ГИА } \\
\text {-Отработка навыков самоорганизации, и самоконтроля } \\
\text {-Формирование рекомендаций кураторам, } \\
\text { педагогам }\end{array}$ \\
\hline $\begin{array}{l}\text { Педагог (руководитель } \\
\text { ДП) }\end{array}$ & $\begin{array}{l}\text {-Формирование позитивного отношения к ГИА } \\
\text {-Формирование конструктивной } \\
\text { стратегии деятельности } \\
\text { по выполнению ВКР } \\
\text {-Развитие умения работать с различными видами } \\
\text { справочной, технической литературой и другими } \\
\text { источниками } \\
\text {-Отработка умения публичного } \\
\text { выступления, репетиция защиты ВКР }\end{array}$ \\
\hline
\end{tabular}

Готовность студента к исследовательской деятельности в комплексе с грамотным руководством и продуманным методическим обеспечением позволит в итоге повысить качество выпускных работ и подготовить конкурентоспособных и критически мыслящих специалистов, готовых к постоянному самосовершенствованию своей профессиональной деятельности и личностному росту на протяжении всей жизни. 